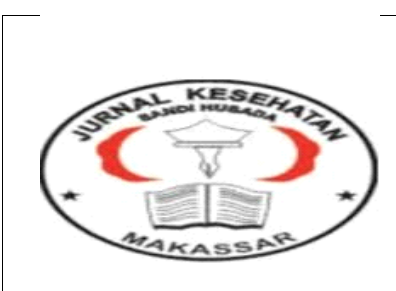

\author{
Jurnal Ilmiah Kesehatan Sandi Husada \\ hhttps://akper-sandikarsa.e-journal.id/JIKSH \\ Vol 11, No, 1, Juni 2020, pp;328-333 \\ p-ISSN: 2354-6093 dan e-ISSN: 2654-4563 \\ DOI: $10.35816 /$ jiskh.v10i2.277
}

\title{
Karakteristik Pasien Ikterus Obstruktif Et Causa Batu Saluran empedu
}

The Patient Characteristics of Obstructive Jaundice Et Causa Stone Gallbladder

\author{
Yusmaidi $^{1}$, Rakhmi Rafie ${ }^{2}$, Annisa Permatasari ${ }^{3}$ \\ ${ }^{1}$ Departemen Bedah Rumah Sakit Abdul Moloek \\ ${ }^{2}$ Departemen Anatomi Fakultas Kedokteran Universitas Malahayati \\ ${ }^{3}$ Program Studi Kedokteran Fakultas Kedokteran Universitas Malahayati \\ Artikel info
}

Artikel history:

Received; 10 April 2020

Revised:14 April 2020

Accepted;23 April 2020

\begin{abstract}
Abstrak
Ikterus Obstruktif merupakan ikterus yang disebabkan oleh obstruksi empedu. Batu saluran empedu merupakan salah satu penyebab ikterus obstruktif yang paling sering.Tujuan penelitian ini adalah mengetahui karakteristik pasien ikterus obstruktif et causa batu saluran empedu di RSUD Dr.H. Abdul Moeloek Bandar Lampung Tahun 2017-2018. Jenis penelitian ini adalah deskriptif retrospektif menggunakan data sekunder dari rekam medik. Sampel penelitian ini menggunakan teknik Purposive Sampling. Sampel penelitian ini sebanyak 35 pasien. Kasus terbanyak menyerang pada kelompok umur 4665 tahun sebanyak 18 pasien (51,4\%)dan 22 pasien (62,9\%) pada perempuan. Keluhan utama dan pemeriksaan fisik terbanyak pada sklera dan kulit ikterik sebanyak 100\%. Dari hasil pemeriksaan laboratorium dan usg didapatkan sebanyak $51,4 \%$ leukosit normal dan gambaran pelebaran saluran empedu intrahepatik sebanyak $85,7 \%$. Penatalaksanaan dilakukan tindakan operatif sebanyak $57,1 \%$. Karakteristik terbanyak ditemukan pada kelompok umur 46-65 tahun, jenis kelamin perempuan dengan keluhan utama dan pemeriksaan fisik yaitu sklera dan kulit ikterik, leukosit normal, gambaran usg terdapat pelebaran saluran empedu intrahepatik, dan dilakukan tindakan operatif.
\end{abstract}

\begin{abstract}
Obstructive jaundice is jaundice caused by bile obstruction. Common bile duct stone are one of the most common causes of obstructive jaundice. The purpose of this study to determine the characteristics of the patients with obstructive jaundice et causa common bile duct stone in RSUD Dr. H. Abdul Moeloek Bandar Lampung in 2017-2018. This study was retrospective descriptive which used secondary data from medical records. Purposive Sampling technique was used to collect the data. The sample of this study were 35 patients. The most common cases attacked 18 patients aged $46-65$ years old $(51,4 \%)$ and
\end{abstract}




\begin{tabular}{|c|c|}
\hline & $\begin{array}{l}22 \text { female patients (62.9\%). The main complaints and physical } \\
\text { examinations were mostly on the sclera and jaundice skin as } \\
\text { much as 100\%. Based on the results of laboratory } \\
\text { examination and ultrasound, it showed that } 51.4 \% \text { normal } \\
\text { leukocytes, } 85.7 \% \text {. intrahepatic bile duct widening and } 57.1 \% \\
\text { operative measures are performed. he characteristics were } \\
\text { mostly in women aged } 51-60 \text { years old with the main } \\
\text { complaints and physical examination were sclera and } \\
\text { jaundice skin, normal leukocytes, intrahepatic bile duct } \\
\text { widening, and operative measures are performed }\end{array}$ \\
\hline $\begin{array}{l}\text { Keywords: } \\
\text { Ikterus; } \\
\text { Obstrukti; } \\
\text { Batu Saluran Empedu; }\end{array}$ & $\begin{array}{l}\text { Coresponden author: } \\
\text { Email: annsprmts03@gmail.com }\end{array}$ \\
\hline
\end{tabular}

\section{Pendahuluan}

Ikterus adalah perubahan warna kulit, sklera mata atau jaringan lainnya (membran mukosa) yang menjadi kuning karena pewarnanaan oleh bilirubin yang meningkat konsentrasinya dalam sirkulasi darah. Ikterus yang ringan dapat dilihat paling awal pada sklera mata dan kalau ini terjadi konsentrasi bilirubin sudah berkisar antara 2-2,5 mg/dL (Sulaiman, 2014). Ikterus obstruktif merupakan ikterus yang disebabkan oleh obstruksi bilier (obstruksi empedu), yaitu tersumbatnya saluran empedu yang membawa cairan empedu dari hati dan kandung empedu menuju usus halus, berbagai penyebab seperti koledocholithiasis, striktur saluran empedu, kolangiokarsinoma, karsinoma pankreas, pankreatitis, parasit dan kolangitis sklerosis primer (Fekaj et al., 2017).

Batu saluran empedu (koledocholithiasis) merupakan salah satu penyebab ikterus obstruktif yang paling sering (Wandling et al., 2016). Penyakit batu empedu merupakan penyakit yang sering dikeluhkan oleh masyarakat Amerika Serikat hingga dirawat di rumah sakit. Di Indonesia diduga prevalensi penyakit batu empedu lebih rendah bila dibandingkan dengan di negara Barat, tetapi dengan adanya kecenderungan sedentary lifestyle kemungkinan di Indonesia pada masa mendatang kasus batu empedu akan menjadi masalah kesehatan yang patut menjadi perhatian. Angka kejadian batu saluran empedu sangat dipengaruhi usia dan jenis kelamin. Batu saluran empedu empat sampai sepuluh kali lebih sering terjadi pada usia tua dibandingkan usia muda. Jumlah penderita perempuan lebih banyak daripada jumlah penderita laki-laki (Tuuk, 2016).

Diagnosis batu saluran empedu cukup sulit dibandingkan penyakit lainnya. Pemeriksaan radiologis sederhana pun tidak mudah menentukan adanya batu pada saluran empedu. Namun untuk membantu diagnosis, tidak ada salahnya untuk dilakukan beberapa pemeriksaan penunjang seperti laboratorium darah dan pemeriksaan radiologis sebagai pertimbangan tertentu (Amelia, 2017).

\section{Metode}

Jenis penelitian yang digunakan dalam penelitian ini adalah deskriptif retrospektif. Penelitian ini dilakukan di RSUD Dr. H. Abdul Moeloek Bandar Lampung pada bulan Januari tahun 2020. Populasi pada penelitian ini meliputi seluruh pasien obstruksi saluran empedu dan batu saluran empedu yang tercatat dalam rekam medik di RSUD Dr. H. Abdul Moeloek Bandar Lampung Periode Januari 2017-Desember 2018 dengan menggunakan tekhnik sampling purposive sampling dan memperhatikan kriteria inklusi dan ekslusi maka didapatkan jumlah sampel sebanyak 35 . 


\section{Hasil dan Pembahasan}

Tabel 1. Distribusi Frekuensi Pasien Ikterus Obstruktif Et Causa Batu Saluran Empedu Berdasarkan Keluhan Utama

\begin{tabular}{lcc}
\hline \multicolumn{1}{c}{ Keluhan Utama } & Jumlah & Persentase (N=35) \\
\hline Sklera dan kulit ikterik & 35 & 100 \\
Urin berwarna gelap tua & 13 & 37.1 \\
Feses pucat & 6 & 17.1 \\
Nyeri perut kanan atas & 33 & 94.3 \\
Mual muntah & 25 & 71.4 \\
\hline
\end{tabular}

Sumber: Data primer, 2020

Tabel 2. Distribusi Frekuensi Pasien Ikterus Obstruktif Et Causa Batu Saluran Empedu Berdasarkan Pemeriksaan Fisik

Pemeriksaan fisik Jumlah Persentase (N=35)

\begin{tabular}{lcc}
\hline Sklera \& kulit ikterik & 35 & 100 \\
Nyeri tekan kuadran kanan atas & 13 & 97.1 \\
Murphy sign & 8 & 22.9 \\
Hepatomegali & 33 & 28.9 \\
\hline
\end{tabular}

Sumber: Data primer, 2020

Tabel 3. Distribusi Frekuensi Pasien Ikterus Obstruktif Et Causa Batu Saluran Empedu Berdasarkan Jumlah Leukosit

\begin{tabular}{ccc}
\hline $\begin{array}{c}\text { Jumlah Leukosit } \\
\left(\mathbf{s e l} / \mathbf{m ~ m}^{\mathbf{3}}\right)\end{array}$ & Jumlah & Persentase \\
\hline $4.000-11.300$ & 18 & 51.4 \\
$>11.300 \quad$ Total & 17 & 48.6 \\
\hline \multicolumn{2}{c}{ Tre } \\
\hline
\end{tabular}

Sumber: Data primer, 2020

Tabel 4. Distribusi Frekuensi Pasien Ikterus Obstruktif Et Causa Batu Saluran Empedu Berdasarkan Gambaran USG

\begin{tabular}{lcc}
\hline \multicolumn{1}{c}{ Gambaran USG } & Jumlah & Persentase(N=35) \\
\hline Batu di saluran empedu & 24 & 68.6 \\
Pelebaran saluran empedu & 30 & 85.7 \\
intrahepatik & & 48.6 \\
Batu single & 17 & 20 \\
Batu multiple & 7 & \\
\hline
\end{tabular}

Sumber: Data primer, 2020

Tabel 5. Distribusi Frekuensi Pasien Ikterus Obstruktif Et Causa Batu Saluran Empedu Berdasarkan Tatalaksana

\begin{tabular}{lccc}
\hline \multicolumn{2}{c}{ Tatalaksana } & Jumlah & Persentase \\
\hline Nonoperatif & & 15 & 42.9 \\
Operatif & Total & 20 & 51.1 \\
\hline & $\mathbf{3 5}$ & $\mathbf{1 0 0}$
\end{tabular}

Sumber: Data primer, 2020 


\section{Ikterus Obstruktif Et Causa Batu Saluran Empedu Berdasarkan Keluhan Utama}

Berdasarkan hasil penelitian didapatkan seluruh pasien batu saluran empedu sebanyak $100 \%$ datang dengan suatu gejala (simptomatik). Tabel 3 menunjukkan bahwa keluhan utama paling banyak dialami pasien ikterus obstruktif et causa batu saluran empedu dari data rekam medik di RSUD Dr. H. Abdul Moeloek Bandar Lampung tahun 2017- 2018 adalah sklera dan kulit ikterik sebanyak 35 pasien (100\%) kemudian diikuti nyeri perut kanan atas sebanyak 33 pasien (94,3\%), mual muntah sebanyak 25 pasien $(71,4 \%)$.

Hasil ini tidak berbeda jauh dengan penelitian yang dilakukan Amelia et al (2017) di RSUP Dr.Hasan Sadikin Bandung didapatkan keluhan utama paling banyak adalah nyeri perut kanan atas disertai kuning pada seluruh tubuh. Penelitian Jiwani et al (2016) juga didapatkan keluhan utama paling banyak yaitu ikterus (98\%), urine berwarna gelap tua dan feses berwarna pucat (88\%), nyeri perut kanan atas (84\%), mual muntah $(62 \%)$. Keluhan ikterus pada sklera dan seluruh tubuh disebabkan oleh batu yang telah menyebabkan sumbatan total pada duktus koledokus, sehingga aliran bilirubin terkonjugasi menjadi terhambat dan masuk kedalam aliran darah, makan pasien mengalami keluhan ikterus episodik karena peningkatan kadar bilirubin dalam darah. Nyeri perut kanan atas disebabkan oleh penekanan batu pada lumen duktus sehingga menyebabkan tekanan intralumen meningkat dan distensi saluran empedu yang pada akhirnya akan merangsang dan mengaktivasi neuron sensori yang menyebabkan terjadinya nyeri kolik. Gagalnya cairan empedu yang masuk menuju usus halus untuk ekskresi menyebakan terlalu banyak bilirubin masuk kedalam kandung kemih sehingga urin berwarna gelap tua. Tinja sering berwarna pucat karena lebih sedikt cairan empedu yang bisa mencapai saluran cerna usus halus (Sulaiman, 2014).

\section{Ikterus Obstruktif Et Causa Batu Saluran Empedu Berdasarkan Pemeriksaan Fisik}

Berdasarkan hasil penelitian diketahui bahwa distribusi frekuensi pasien ikterus obstruktif et causa batu saluran empedu berdasarkan pemeriksaan fisik dari data rekam medik di RSUD Dr. H. Abdul Moeloek Bandar Lampung tahun 2017-2018 pada sklera dan kulit ikterik sebanyak 35 pasien (100\%) diikuti nyeri tekan perut kanan atas sebanyak 34 pasien $(97,1 \%)$ dan terendah terdapat pada murphy sign sebanyak 8 pasien $(22,9 \%)$. Sesuai dengan penelitian Rai \& Kumar (2017) didapatkan pemeriksaan fisik terbanyak yaitu ikterik sebanyak 17 pasien (74\%) dan nyeri tekan perut kanan atas sebanyak 15 pasien (65\%).

Menurut teori Nurman, pemeriksaan fisik paling sering ditemukan pada batu saluran empedu yaitu ditemukan nyeri tekan perut kanan atas dan penyakit kuning. Gianawati et al melakukan penelitian di RSUPN Dr.Cipto Mangunkusumo Jakarta menemukan tanda-tanda klinisnya adalah sklera ikterik, hepatomegali ringan, nyeri tekan perut kanan atas, murphy sign positif.

\section{Ikterus Obstruktif Et Causa Batu Saluran Empedu Berdasarkan Jumlah Leukosit}

Berdasarkan hasil penelitian diketahui bahwa distribusi frekuensi pasien ikterus obstruktif et causa batu saluran empedu berdasarkan jumlah leukosit dari data rekam medik di RSUD Dr. H. Abdul Moeloek Bandar Lampung tahun 2017-2018 pada jumlah leukosit 4.400-11.300 (normal) sebanyak 18 pasien (51,4\%) dan lebih dari 11.300 (leukositosis) sebanyak 17 pasien (48,6\%). Gambaran hitung jumlah leukosit didukung oleh nilai tengah hitung yaitu $9.520 \mathrm{sel} / \mathrm{mm} 3$ dengan rata-rata $11.826 \mathrm{sel} / \mathrm{mm} 3$. Hitung jumlah leukosit terendah dari pasien yang diteliti adalah $6.200 \mathrm{sel} / \mathrm{mm} 3$ dan tertinggi sebesar $27.400 \mathrm{sel} / \mathrm{mm} 3$.

Hasil ini tidak jauh berbeda dengan penelitian yang dilakukan Amelia (2017) di RSUP Dr. Hasan Sadikin Bandung periode Januari 2014-Desember 2016 didapatkan leukosit normal 
sebanyak $68 \%$ dan leukositosis sebanyak 32\%. Pasien batu saluran empedu mengalami leukositosis. Hal ini disebabkan oleh sumbatan batu yang terjadi dapat mencetuskan kerusakan jaringan sekitarnya dan menyebabkan respon inflamasi sehingga kadar leukosit pun meningkat. Sel darah putih ini berfungsi untuk membantu tubuh melawan berbagai penyakit infeksi sebagai bagian dari sistem kekebalan tubuh.

\section{Ikterus Obstruktif Et Causa Batu Saluran Empedu Berdasarkan Gambaran USG}

Berdasarkan hasil penelitian diketahui bahwa distribusi frekuensi pasien ikterus obstruktif et causa batu saluran empedu berdasarkan gambaran USG dari data rekam medik di RSUD Dr. H. Abdul Moeloek Bandar Lampung tahun 2017-2018 didapatkan pelebaran saluran empedu intrahepatik sebanyak 32 pasien $(91,4 \%)$, batu di saluran empedu sebanyak 24 pasien $(68,6 \%)$, batu single sebanyak 17 pasien $(48,6 \%)$, dan batu multiple sebanyak 7 pasien $(20 \%)$.

Hasil ini tidak jauh berbeda dengan penelitian Jiwani et al (2016) didapatkan batu yang terdeteksi di saluran empedu menggunakan USG sebanyak 61,36\%, batu single sebanyak $45,5 \%$, dan batu multiple sebanyak 16\%. Penelitian Orman et al (2018) di Rumah Sakit Universitas Medeniyet Istanbul Turki periode Juni 2014 - Juni 2015 didapatkan pelebaran saluran empedu sebanyak 66,2\%. Orman et al (2018) menyatakan USG banyak digunakan sebagai alat pemeriksaan awal untuk diagnosis batu saluran empedu karena memiliki keuntungan seperti non invasive, mudah didapat, dan biaya murah. Tingkat akurasi USG dilaporkan mulai dari 20\%-80\% dalam banyak penelitian dan itu tingkat keberhasilan yang rendah untuk memprediksi koledokolitiasis.Sensitivitas, spesifisitas, dan nilai prediktif positif dan negative ultrasonografi dalam mendeteksi batu saluran empedu.

Dalam penelitian Ankur Mandelia et al masing-masing adalah 65\%, 60\%, 76.47\%, dan $46.15 \%$ dan Jiwani et al masing-masing adalah 61.6\%, 96.43\%, dan 81\%. USG tidak dapat mendeteksi kalkulus atau batu karena pasien berlemak dan keberadaan gas dalam duodenum yang berlebihan. USG adalah modalitas pemeriksaan penunjang primer namun MRCP dan ERCP merupakan pemeriksaan baku emas (gold standard) untuk diagnosis ikterus obstruktif et causa batu saluran empedu (Jiwani et al., 2016).

\section{Ikterus Obstruktif Et Causa Batu Saluran Empedu Berdasarkan Tatalaksana}

Berdasarkan hasil penelitian diketahui bahwa distribusi frekuensi pasien ikterus obstruktif et causa batu saluran empedu berdasarkan tatalaksana dari data rekam medik di RSUD Dr. H. Abdul Moeloek Bandar Lampung tahun 2017-2018 tertinggi yaitu pasien yang telah dilakukan tindakan operatif sebanyak 20 pasien $(57,1 \%)$ dan terendah adalah nonoperatif sebanyak 15 pasien $(42,9 \%)$.

Menurut Lesmana (2014) prosedur terapetik yang bertujuan untuk mengangkat batu CBD ada dua cara, pertama operasi dengan melakukan sayatan pada CBD (koledekotomi), atau melalui duktus sistikus (transistik), dengan metode konvensional operasi terbuka (Open Common Bile Duct Exploration) ataupun melalui laparoskopi yang disebut Laparascopic Common Bile Duct Exploration (CBDE). Laparoskopi kolesistektomi saat ini memang lebih banyak disukai dan sudah menjadi terapi standar. Sedangkan cara yang kedua adalah dengan menggunakan endoskopi, yaitu Endoscopic Retrograde Cholangiopancreatography (ERCP) yang diikuti sfingterotomi endoskopik (ES) dan dilakukan ekstraksi batu. Penggunaan ERCP telah diterima sebagai pengobatan pilihan sebelum kolesistektomi pada pasien dengan batu empedu dan batu saluran empedu. ERCP meminimalisir pembedahan pada pasien batu empedu dan batu saluran empedu. Dengan pencitraan diagnostik yang lebih baru teknologi yang muncul, ERCP berkembang menjadi prosedur terapi yang dominan. ERCP berhasil dapat dicapai pada lebih dari $90 \%$ pasien. Di era ini, ERCP dapat dilakukan sebelum atau bahkan sesudahnya kolesistektomi laparoskopi, jika batu tidak 
bisa dibersihkan dengan eksplorasi saluran umum. Berdasarkan penelitian Sanchez et al diketahui bahwa laparoscopy dan laparoscopy common bile duct exploration merupakan terapi yang tidak disukai secara luas di kalangan komunitas bedah, karena hanya ahli bedah laparoskopi mungkin dapat melakukannya.

\section{Simpulan Dan Saran}

Karakteristik terbanyak ditemukan pada kelompok umur 46-65 tahun, jenis kelamin perempuan dengan keluhan utama dan pemeriksaan fisik yaitu sklera dan kulit ikterik, leukosit normal, gambaran usg terdapat pelebaran saluran empedu intrahepatik, dan dilakukan tindakan operatif. Penelitian sebaiknya dapat dilanjutkan dengan sampel yang lebih banyak serta diharapkan dapat menggunakan hasil penelitian ini sebagai dasar penelitian untuk melakukan penelitian selanjutnya. Bagi instansi kesehatan, diharapkan melakukan penyuluhan rutin kepada masyarakat dan memberikan edukasi kepada pasien agar dapat menurunkan angka risiko ikterus obstruktif et causa batu saluran empedu

\section{Daftar Rujukan}

Amelia, D. N. (2017). Gambaran Pasien Koledokolitiasis Di Bagian Bedah Digestif Rsup Dr. Hasan Sadikin Bandung Periode Januari 2014-Desember 2016.

Fekaj, E., Jankulosvki, N., Matveeva, N. (2017). Obstructive Jaundice. Austin Digestive System. 2(1): 1006.

Jiwani, M. S. A., Kharche, A., \& Jiwani, A. A. (2016). Role of MRCP and USG in Cases of Choledocholithiasis. International Journal of Science and Research, 5(10), 11901197

Kurian , J. M., John , P. K., K, G., Hegde, P., Murthy, C., Kumar, A. (2017). Assessment of clinical profile of patients with obstructive jaundice. International Journal of Contemporary Medical Research, 4(1), 197-200.

Lesmana, L. 2014. Batu Empedu. In: Sudoyo,A.W., Setiyohadi, B.,Alwi, I., Simadibrata, M., Setiati, S., editors. Buku Ajar Penyakit Dalam. Jilid 2. 6th.Ed. Balai Penerbit Fakultas Kedokteran Universitas Indonesia.p.380-384.

Orman, S., Senates, E., Ulasoglu, C., \& Tuncer, I. (2018). Accuracy of Imaging Modalities in Choledocholithiasis: A Real-Life Data. International Surgery, 103(3), 177-183.

Rai, M. K., \& Kumar, V. (2017). Incidence of choledocholithiasis in gallstone disease in the eastern zone of India: A single centre study. Int J Med and Dent Sci, 6(1), 1417-1420.

Sanchez, A., Rodriguez, O., Bellorín, O., Sánchez, R., \& Benítez, G. (2010). Laparoscopic common bile duct exploration in patients with gallstones and choledocholithiasis. JSLS: Journal of the Society of Laparoendoscopic Surgeons, 14(2), 246.

Sulaiman, Ali. 2014. Pendekatan klinis pada pasien ikterus. In: Aru W Sudoyo, et al. Buku ajar ilmu penyakit dalam Jilid 2. $6^{\text {th }}$ Ed. Jakarta: Penerbitan FKUI

Tuuk, A. L., Panelewen, J., \& Noersasongko, A. D. (2016). Profil kasus batu empedu di RSUP Prof. Dr. RD Kandou Manado periode Oktober 2015-Oktober 2016. e-CliniC, 4(2).

Wandling, M. W., Hungness, E. S., Pavey, E. S., Stulberg, J. J., Schwab, B., Yang, A. D., ... \& Nathens, A. B. (2016). Nationwide assessment of trends in choledocholithiasis management in the United States from 1998 to 2013. JAMA surgery, 151(12), 1125-1130. 